\title{
EXTRACTION OF STEVIOL GLYCOSIDES FROM DRIED STEVIA REBAUDIANA BY PRESSURIZED HOT WATER EXTRACTION
}

\author{
Á. NÉMETH* and Sz. JÁNOSI \\ Fermentation Pilot Plant Laboratory, Department of Applied Biotechnology and Food Science, Budapest \\ University of Technology and Economics, H-1111 Budapest, Müegyetem rkp. 3. Hungary
}

(Received: 11 July 2018; accepted: 9 October 2018)

\begin{abstract}
In existing processes, the extraction of steviol glycosides from stevia leaves involves many process steps often including extraction by organic solvents. The purpose of the present study was to develop a process for the effective extraction of steviol glycosides, which can provide a concentrated juice exhibiting a high level of recovery with regard to the target compounds, rebaudioside A and stevioside. Pressurized Hot Water Extraction (PHWE) was first optimized with Response Surface Methodology in terms of maximized rebaudioside-A yield and minimized colour components. PHWE was then combined with pressing in a wine-press, resulting higher efficiency for extracting both steviol glycosides in comparison to the reported methods in the literature. Finally, spray drying was applied for both product stabilization and removal of contaminants.

Keywords: Stevia rebaudiana, stevioside, rebaudioside A, pressurized hot water extraction, pressing, spray drying
\end{abstract}

The consumption of carbohydrates, including sugar usage, is gaining increased attention on account of obesity and diabetes (KeARnEy, 2010). The increased availability of sugar has facilitated an increasing number of energy-rich, high-calorie foodstuffs on the market. This has had a detrimental effect on those trying to lead a healthy lifestyle. As a result, there is a need for low-calorie natural sweeteners, which can replace sucrose (Lê et al., 2016). Today, many artificial sweeteners exist, e.g. aspartame, saccharin, sucralose, cyclamate, etc., which play no role in terms of energy supply, only with regard to sweetening. However, these sweeteners cannot match the taste of real sugar, and during the application of these ingredients medical side effects can arise. Therefore, the goal is to make an alternative sweetener, which complies with all these requirements.

On the other hand, there are several natural low-calorie sweeteners found in nature that, when consumed, are capable of avoiding the above-mentioned side effects. Most of them are extracted from plants, and their sweet flavour has been used in some cultures since ancient times, e.g. agave nectar, monk fruit, maple syrup, etc., but the industrial extraction of them is not common, because sugar is cheap and easily available.

The plant Stevia rebaudiana grows naturally in South America. Substances produced by extraction from stevia are about 300 times sweeter than sucrose. Stevia has been used for centuries by the indigenous Guarani tribe as a sweetener and a herbal tea to treat heartburn and other complaints. The plant belongs to the Asteraceae family. More than 230 species belong to the genus Stevia, but only the species phlebophylla and rebaudiana produce components with sweet taste (Lemus-MondaCA et al., 2012).

\footnotetext{
* To whom correspondence should be addressed.

Phone: +36 1463 2595; fax: +36 1463 3855; e-mail: naron@f-labor.mkt.bme.hu
}

0139-3006 (c) 2019 The Author(s) 
The sweet taste is caused by the accumulation of diterpene glycosides. In addition, beside its sweet components, the plant contains a number of other important compounds, e.g. tannins, flavonoids, alkaloids, lipids, vitamins, minerals, and essential oils (SERFATY et al., 2013).

The plant contains eight different steviol glycosides: stevioside, steviolbioside, rebaudioside- $\mathrm{A},-\mathrm{B},-\mathrm{C},-\mathrm{D},-\mathrm{E}$, and dulcoside $\mathrm{A}$. The most common is stevioside, which comprises $4-13 \%$ of the plant dry matter and rebaudioside $A$, which can be found in $2-4 \%$. These are followed by rebaudioside- $\mathrm{C}(1-2 \%)$ and dulcoside $\mathrm{A}(0.4-0.7 \%)$. Rebaudioside-B, $-\mathrm{D},-\mathrm{E},-\mathrm{F}$, and steviolbioside are present in the plant as minor components. These molecules are highly stable in aqueous solutions over a wide $\mathrm{pH}$ as well as temperature range. They are not directly fermentable. Steviosides are broken down by intestinal bacterial flora into aglycone (i.e. steviol) and sugar, but the sugar is not absorbed in the colon, so steviol glycosides possess a zero-energy content (LEMUS-MondACA et al., 2012).

Because of the beneficial effects mentioned above, a number of studies have already realized the extraction of steviol glycosides from the stevia plant species (see Table 1). These include traditional and up to date procedures.

Table 1. Overview of different stevia extraction methods

\begin{tabular}{|c|c|c|c|c|c|}
\hline & $\begin{array}{c}\text { Obtained } \\
\text { stevioside } \\
\left.\text { (mg g } \mathrm{m}^{-1} \text { plant }\right)\end{array}$ & $\begin{array}{c}\text { Obtained } \\
\text { rebaudioside-A } \\
\left(\mathrm{mg} \mathrm{g}^{-1} \text { plant }\right)\end{array}$ & $\begin{array}{c}\text { Obtained } \\
\text { stevioside } \\
\left(\mathrm{g} \mathrm{l}^{-1} \text { solvent }\right)\end{array}$ & $\begin{array}{l}\text { Obtained } \\
\text { rebaudioside-A } \\
\left(\mathrm{g}^{-1} \text { solvent }\right)\end{array}$ & Reference \\
\hline Soxhlet-extraction & 81 & 37 & 1.62 & 0.74 & $\begin{array}{l}\text { MAKAPUGAY et al., } \\
1984\end{array}$ \\
\hline Extraction with alcohol & 84.3 & 31.8 & 0.84 & 0.32 & VANĚK et al., 2001 \\
\hline Extraction with water & 4.9 & 1.47 & 0.245 & 0.0736 & Kutowy et al., 1999 \\
\hline $\begin{array}{l}\text { Ultrasound supported } \\
\text { extraction }\end{array}$ & 73.72 & 48.77 & 7.37 & 4.88 & Liu et al., 2010 \\
\hline $\begin{array}{l}\text { Microwave assisted } \\
\text { extraction }\end{array}$ & 86.4 & 23.4 & 0.86 & 0.23 & JAITAK et al., 2009 \\
\hline $\begin{array}{l}\text { High pressure liquid } \\
\text { extraction (PFE) with } \\
\text { methanol }\end{array}$ & 115 & n.a. & n.a. & n.a. & Pól et al., 2007 \\
\hline $\begin{array}{l}\text { High pressure liquid } \\
\text { extraction (PFE) with } \\
\text { water } 1 .\end{array}$ & 110 & n.a. & n.a. & n.a. & Pól et al., 2007 \\
\hline $\begin{array}{l}\text { High pressure liquid } \\
\text { extraction (PFE) with } \\
\text { water } 2 \text {. }\end{array}$ & 109 & 26 & n.a. & n.a. & RAO et al., 2012 \\
\hline $\begin{array}{l}\text { Supercritical fluid } \\
\text { extraction }\end{array}$ & 36.6 & 17.79 & n.a. & n.a. & ERKUCUK et al., 2009 \\
\hline $\begin{array}{l}\text { Enzyme assisted } \\
\text { extraction }\end{array}$ & 0.925 & n.a. & n.a. & n.a. & PURI et al., 2012 \\
\hline
\end{tabular}

n.a.: not available 
Conventional procedures include Soxhlet extraction, which uses chloroform and methanol as well as alcoholic and simple aqueous extraction. Using these procedures, good results can be achieved, but the majority of them are time-consuming and complicated processes involving many organic solvents, which are not really environmentally friendly (MaKapugay et al., 1984; KolB et al., 2001). Recent methods such as different pressurized extractions (PFE: Pól et al., 2007; PHWE: RAO et al., 2012), supercritical fluid extraction (ERKUCUK et al., 2009), microwave- (JAITAK et al., 2009) and ultrasound-assisted extractions (LiU et al., 2010) can provide great opportunities for the recovery of steviol glycosides. In recent years, the extraction of bioactive molecules from plants by enzyme-assisted processes has been developed. To aid extraction, cell wall degrading enzymes, e.g. cellulase, pectinase, and hemicellulase, can be used (Puri et al., 2012).

Among the techniques listed in Table 1, the second most efficient one was ultrasoundassisted extraction, while the best results were achieved using PFE and PHWE. The advantages of PFE and PHWE are their low time- and solvent consumption. By regulating the pressure, the extraction was carried out at elevated temperatures, above the atmospheric boiling point of the solvent. Due to elevated pressures, which exceeded atmospheric pressure but were below the solvent's critical value, the solvent is in liquid phase, but the application of high temperatures makes this technique only applicable to thermally stable compounds. While high temperatures increase the solubility of the target compound in the solvent, elevated pressures increase the rate of diffusion across the pores of the matrix as well, thus facilitating the transition of the target molecule into the solvent. Pól and co-workers (2007) studied two PFE extractions, one with methanol and the other with water. The results showed that the two solvents yielded similar results, but considering that water is more environmental friendly than methanol, its application is recommended.

Raw stevia extract contains several impurities as concomitant compounds of sweetening agents. These may include phenolic compounds, flavour-, aroma-, and colouring agents as well as pigments. Because of these compounds, purification is a crucial step in the development of stevia extraction technology. According to ZHANG and co-workers (2000) and CHHAYA and co-workers (2012), the most important purification techniques are membrane-based separations, clarification by activated carbon (RAJAB et al., 2009), and chromatographic operations (KUMARI et al., 2017).

According to several patents (Kutowy et al., 1999; MARKosyan, 2012), spray drying is an excellent final step of this technology, since the bitter aftertaste of steviosides can be minimized and the properties that comprise the composition of the sweetener improved. This technique is capable of optimizing the moisture content and increasing the chemical stability.

A more recent study (MATHUR et al., 2017) summarized the existing patents on stevia extraction techniques. These either use organic solvents or purified aqueous extracts on ionexchange resins, as well as membranes to purify aqueous extracts.

The aim of the present study is to develop a highly efficient technique for the recovery of steviol glycosides from stevia leaves via simple and environmental friendly processes. To achieve this, pressurized hot water extraction (PHWE) was carried out on dried stevia leaves that were then pressed and finally spray dried. The optimal setup for PHWE was examined using a Taguchi factorial design on an output factor, which combined the concentration of the product and the colour of the extract. It was intended to elaborate an efficient extraction method due to maximizing the product yield and minimizing disliked substances at the same time. 


\section{Materials and methods}

\subsection{Plant material}

Stevia rebaudiana Bertoni leaves were harvested from the plantations in Orosháza in Hungary during the summer of 2012. The leaves were dried in a room ventilated by air at a temperature of $25 \pm 2{ }^{\circ} \mathrm{C}$ for two weeks and then stored at room temperature in plastic bags to have constant quality raw material.

\subsection{Chemicals}

Stevioside and rebaudioside-A standards were purchased from Sigma-Aldrich Co (USA). Tap water was used as an extraction medium for PHWE. High performance liquid chromatography (HPLC)-grade acetonitrile (Merck, USA) and $\mathrm{KH}_{2} \mathrm{PO}_{4}$ (Biolab Inc., Hungary) buffers were used for the HPLC analysis.

\subsection{HPLC analysis}

The concentration of steviol glycosides in the leaf extracts and other samples were quantified by Waters (Waters Co, USA) HPLC using a Waters 1515 isocratic HPLC Pump, a Waters 717 plus autosampler, and a Waters 2487 UV detector. A ZORBAX Carbohydrate Analysis column (Agilent Technologies, USA) was applied according to the recommended method of the manufacturer (HENDERSON \& BERRY, 2009) with the mobile phase comprised of $0.04 \mathrm{M}$ $\mathrm{KH}_{2} \mathrm{PO}_{4}$ buffer and acetonitrile (25:75). Isocratic elution was performed with a flow rate of

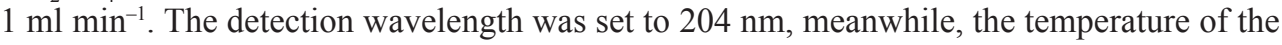
column was set to $30^{\circ} \mathrm{C}$.

Standards were dissolved in deionized water. Five concentrations were prepared from the rebaudioside-A standard $\left(5 ; 2.5 ; 1.25 ; 0.625 ; 0.3125 \mathrm{~g} \mathrm{l}^{-1}\right)$ and three concentrations were prepared from the stevioside standard $\left(1.875 ; 0.9375 ; 0.4686 \mathrm{~g} \mathrm{l}^{-1}\right)$.

\subsection{Measuring of colour formation}

LKB Ultrospec plus spectrophotometer (LKB AB, Sweden) was used at $420 \mathrm{~nm}$ to measure optical absorbance after appropriate dilution of the coloured contaminants in a $4 \mathrm{ml}$ plastic cuvette according to Zhang's method (ZHANG et al., 2000).

\subsection{Extraction of steviol glycosides}

Since the main goal of our experiments was to fulfil an experimental design for steviol glycosides extraction, $1 \mathrm{~g}$ of dried stevia leaves were placed in an Erlenmeyer flask and the corresponding volume of tap water according to the statistical design was added to reach the desired solvent ratio. Finally, the flask was placed into the autoclave (Tuttnauer 3870ELV, The Netherlands), and the extraction was carried out at various regulated pressures. With regard to the design and evaluation of the experiment, Minitab 14 software was used.

For scale up experiment, $200 \mathrm{~g}$ of dried leaves were placed in a 21 Erlenmeyer flask, $1000 \mathrm{ml}$ of tap water was added, and it was autoclaved at a temperature of $121{ }^{\circ} \mathrm{C}$ and a pressure of 2.01 bar for $20 \mathrm{~min}$. 


\subsection{Pressing}

After the extraction (i.e. autoclaving) of $200 \mathrm{~g}$ dried leaves, the wet and hot leaves were pressed using a 21 wine press to obtain the primer juice and separate the liquor from the residue of the leaves. This operation resulted $650 \mathrm{ml}$ of dark brown primer juice.

\subsection{Spray drying}

The raw extract was stabilized using spray drying. A BÜCHI Mini Spray-drier (Büchi, Switzerland) was used with an inlet air temperature of $125^{\circ} \mathrm{C}$, an outlet air temperature of $67^{\circ} \mathrm{C}$, the feeding pump set at $20 \%$ of maximal power, and a compressed air flow rate of $400 \mathrm{l} \mathrm{h}^{-1}$. This set of parameters was established on the basis of a preliminary experiment that used a small fraction of the same raw material with the goal of elaborating a process as rapid as possible without clogging or having condensate formation on the glass wall of the dryer. The products in powdered form were collected at the bottom of the dryer's cyclone and were stored in tightly closed plastic bottles, which were maintained at room temperature, in a dry and dark place at $55 \%$ of relative humidity.

\section{Results and discussion}

The initial step of a cost-effective extraction process is the selection of an appropriate technique. Pressurized Hot Water Extraction (PHWE) uses the most simple and environment friendly solvent, water. Since the solvent characteristics vary with temperature and pressure, parameters have to be selected carefully (PlAZA \& TURNER, 2015). In our experiments, a strong correlation between the concentrations of stevioside and rebaudioside-A in the extracted juice was observed (see Fig. 1), but since rebaudioside-A is the preferred component having strongest sweet taste with the weakest bitter aftertaste (SINGLA \& JAITAK, 2016), rebaudioside-A was the focus of the further evaluation.

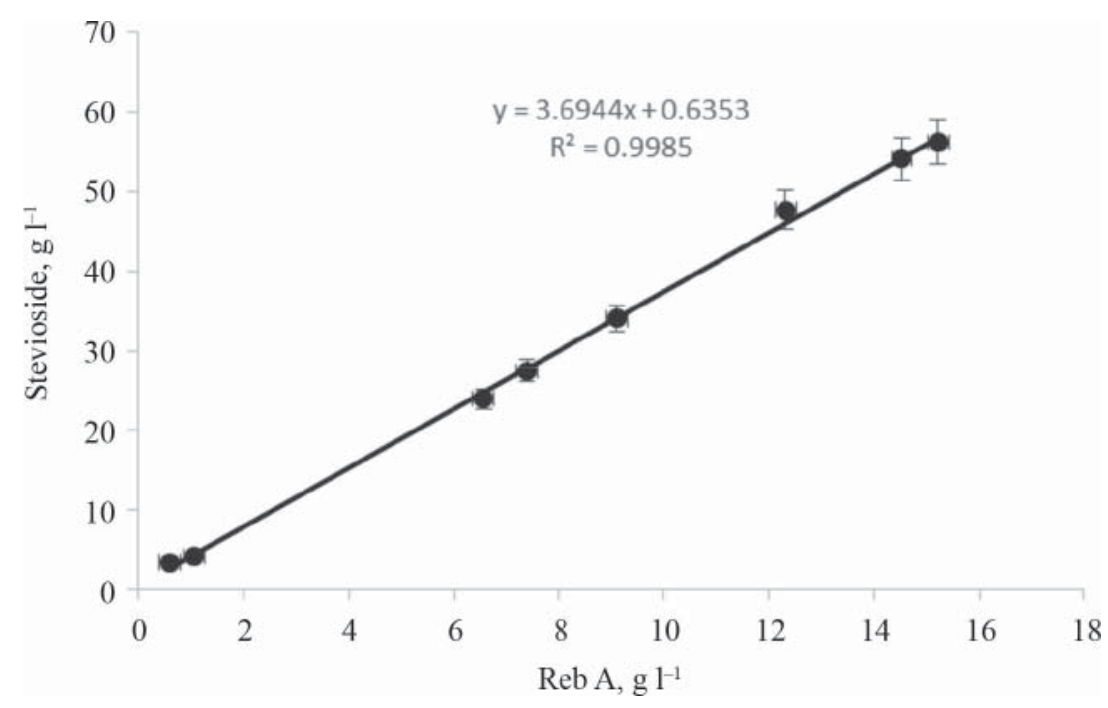

Fig. 1. Correlation between the rebaudioside-A and stevioside contents of the extracts 
Table 2 shows the experimental setup with factors and their uncoded factor's level, and with measured outputs as well as calculated results. The applied pressure $\left(\mathrm{X}_{1}\right)$, extraction time $\left(\mathrm{X}_{2}\right)$, and dry leaves to water ratio $\left(\mathrm{X}_{3}\right)$ were used as factors, and all of them were examined at 3 levels. Extracted solutions were analysed by HPLC to measure the Reb A concentration, and with a photometer to detect coloured contaminants. The results were evaluated through a combined quotient value of Reb A divided by $\mathrm{A}_{420}$ to achieve the highest Reb A concentration together with the lowest degree of colour formation. A Response Surface Model (RSM) was fitted to the results (combined value), and for regression analysis, residuums were first calculated then checked for normality: since in Fig. 2A residuum values are close to a straight line (no outliers etc.), and in Fig. 2B the residuums' histogram shows normal distribution, measurement errors also have normal distribution. Further statistical observations revealed that the differences between measured and fitted data (i.e. residuum) have constant variance (Fig. 2C, data points are in a symmetric range) and are independent from each other, since no tendency can be observed in Fig. 2D.

A: Normal probability plot of the residuals

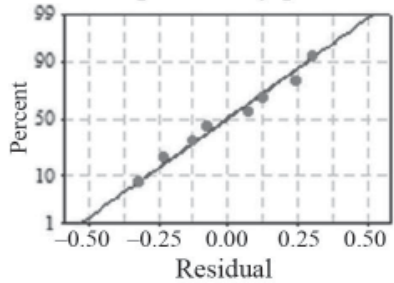

B: Histogram of the residuals

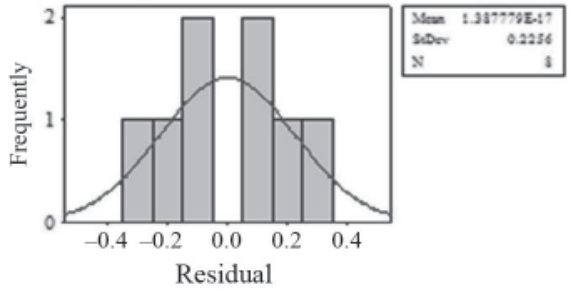

C: Residuals versus the fitted values

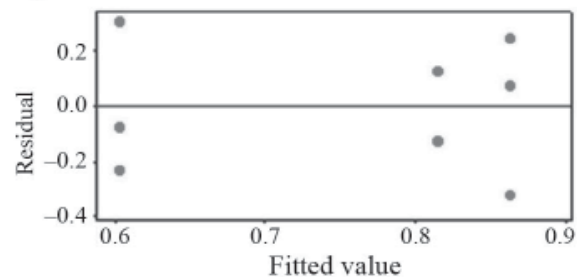

D: Residuals versus the order of the data

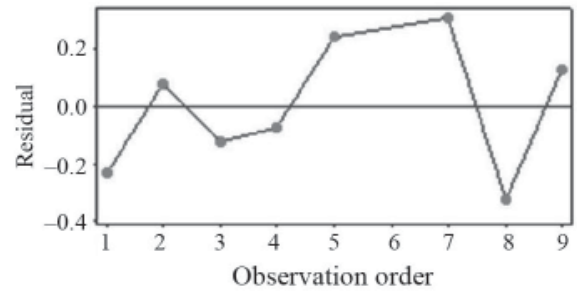

One-way ANOVA, Factor: Time, min

Fig. 2. Statistical examinations of the RSM results. Residual plots of combined value

\subsection{Evaluation of the RSM design}

To find a good equation describing the correlation between the examined factors and the output parameter (i.e. RebA/ $\mathrm{A}_{420}$ ) a general equation was fitted to the results including all examined factors on both the $1^{\text {st }}$ and $2^{\text {nd }}$ order as well as their interaction. During regression, coefficients were determined by the software, and the fitted model equation with the best fitted parameters is given in Eq. 1:

$$
\begin{gathered}
\hat{Y}=6.3837-7.6910 \times X_{1}+0.0068 \times X_{2}+0.0745 \times X_{3}+1.9743 \times X_{1}^{2}-0.0031 \times X_{2}^{2}- \\
-0.0014 \times X_{3}^{2}+0.0667 \times X_{1} \times X_{2}
\end{gathered}
$$

where $X_{1}$ represents pressure, $X_{2}$ time, and $X_{3}$ dry matter to solvent ratio. 
Table 2. Taguchi experimental design for studying the effect of factors on the achieved Reb-A concentration in

\begin{tabular}{|c|c|c|c|c|c|c|c|c|c|}
\hline No. & $\begin{array}{c}\text { Pressure } \\
\text { bar }\end{array}$ & $\begin{array}{l}\text { Time } \\
\min \end{array}$ & $\begin{array}{c}\text { d.m.: solvent } \\
\mathrm{g} \mathrm{ml}^{-1}\end{array}$ & $\begin{array}{c}\text { Reb A } \\
\mathrm{g} \mathrm{l}^{-1}\end{array}$ & $\begin{array}{c}\text { Reb A } \\
\mathrm{g} \mathrm{g}^{-1} \text { of } \\
\text { dried plant }\end{array}$ & $\mathrm{A}_{420}$ & $\begin{array}{c}\text { Combined value } \\
(\mathrm{g} \text { Reb } \mathrm{A}) \\
\left(\mathrm{A}_{420}\right)^{-1}\end{array}$ & Fitted values & Residues \\
\hline 1 & 1.33 & 10 & 0.01 & 0.59 & 0.0587 & 1.59 & 0.37 & 0.370002891 & $-2.891 \mathrm{E}-06$ \\
\hline 2 & 1.33 & 20 & 0.1 & 7.39 & 0.0739 & 7.90 & 0.94 & 0.940003401 & $-3.401 \mathrm{E}-06$ \\
\hline 3 & 1.33 & 30 & 0.2 & 15.21 & 0.0761 & 21.98 & 0.69 & 0.690004811 & $-4.811 \mathrm{E}-06$ \\
\hline 4 & 1.66 & 10 & 0.1 & 6.56 & 0.0656 & 12.35 & 0.53 & 0.530005044 & $-5.044 \mathrm{E}-06$ \\
\hline 5 & 1.66 & 20 & 0.2 & 12.31 & 0.0616 & 11.09 & 1.11 & 1.110006564 & $-6.564 \mathrm{E}-06$ \\
\hline 6 & 1.66 & 30 & 0.01 & - & - & 1.46 & - & & \\
\hline 7 & 1.99 & 10 & 0.2 & 14.53 & 0.0726 & 15.91 & 0.91 & 0.910008459 & $-8.459 \mathrm{E}-06$ \\
\hline 8 & 1.99 & 20 & 0.01 & 1.06 & 0.1063 & 1.95 & 0.54 & 0.540007989 & $-7.989 \mathrm{E}-06$ \\
\hline 9 & 1.99 & 30 & 0.1 & 9.11 & 0.0911 & 9.65 & 0.94 & 0.940008719 & $-8.719 \mathrm{E}-06$ \\
\hline
\end{tabular}

d.m.: solvent: dry matter ratio to solvent volume

As it has been shown in Table 2, the values in the "Fitted" column are very similar to the "Combined" values (calculated from measured Reb A and $\mathrm{A}_{420}$ values), therefore, residuums have very small values. The fitted surfaces above factor-pair plans are represented in Fig. $3 \mathrm{~A}-\mathrm{C}$.

All 3 graphs above suggest an optimum pressure of 2 bars, a reaction time of $20 \mathrm{~min}$, and an optimum dry matter content to solvent ratio at $20 \%$ (which is also a technological optimum, since materials having higher ratio are impractical because of unstirrable behaviour etc.).

\subsection{Evaluation of the Main Effects Plots in terms of Combined Values}

Data means of Means plots in Fig. 4A-C visualize the effects more simply than RSM. Figure 4A, B, and C represent the observed concentration of Reb A, coloured substances (A420), and Combined Values versus tested factors, respectively. It can be stated that the tendencies of Reb A to maximize and A420 to minimize are similar, but their ratios suggest more remarkable changes with regard to these factors.

Reb A-based evaluation (see Fig. 4A) showed that the pressure had no effect over the examined range. However, the concentration of Reb A increased as both time and dry matter content rose.

Meanwhile, pressure and time have no effect on colour formation over the examined range, but a minimum level of $\mathrm{A}_{420}$ was observed at medium levels of factors, i.e. 0.66 bar and 20 min (see Fig. 4B).

Since our goal is to obtain the maximum concentration of Reb A with the minimum degree of colour formation (i.e. $\mathrm{A}_{420}$ ), evaluation of their combined value should obtain special interest (Fig. 4C). Optimal results are achieved at a pressure of 1.66 bars over a time period of $20 \mathrm{~min}$ using $20 \%$ of dry leaves (i.e. $100 \mathrm{mg}$ per $\mathrm{ml}$ of water as a solvent).

Considering all results above and the fact that 2 bar is generally used for sterilization, for larger scale experiments we chose 2 bars, $20 \mathrm{~min}$, and $20 \%$. 
A

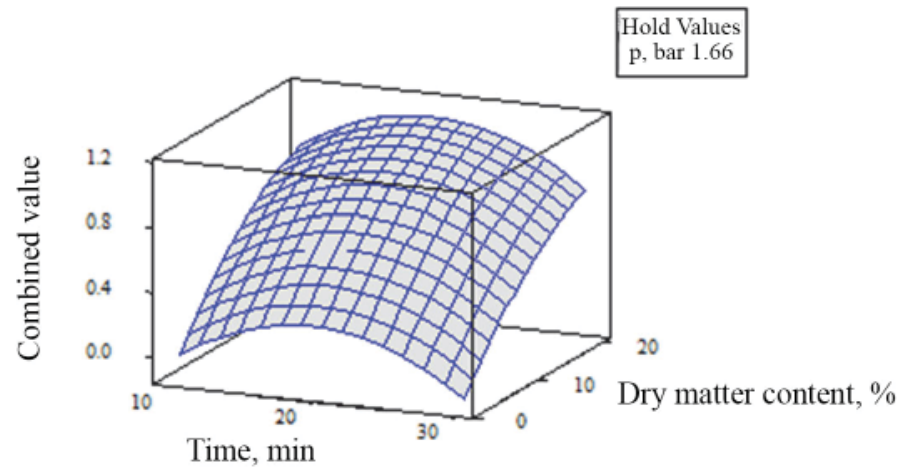

B

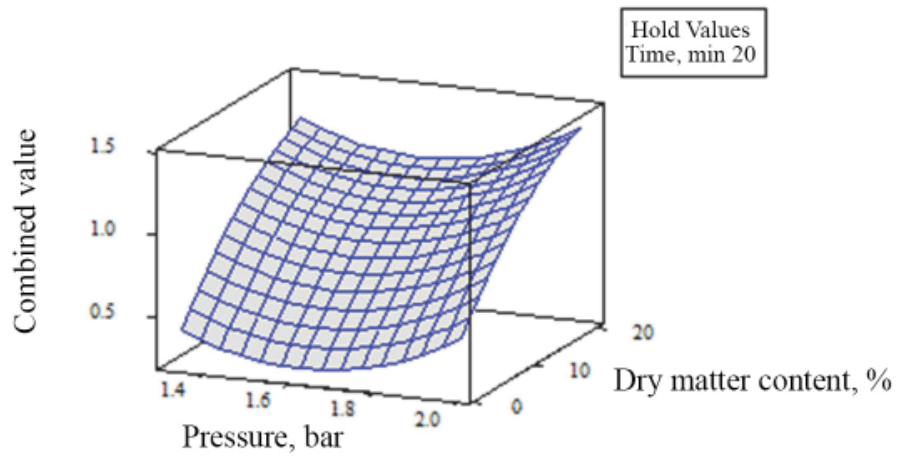

C

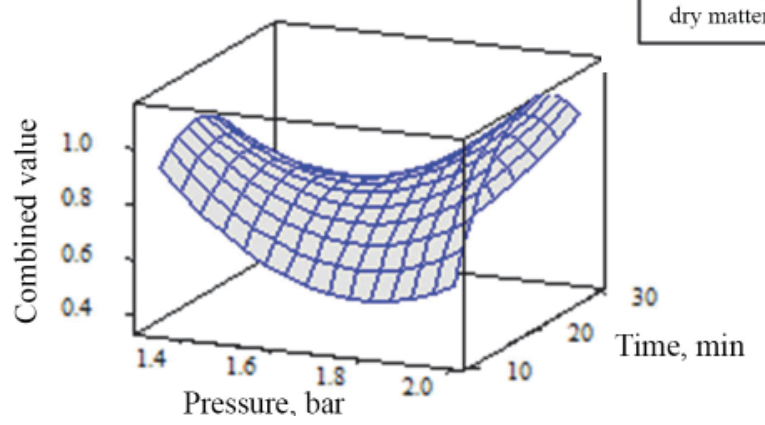

Fig. 3. Surface plots of RSM.

A: Surface plot of combined value vs dry matter content, $\%$ and time, min; B: surface plot of combined value vs dry matter content, $\%$ and pressure, bar; C: surface plot of combined value vs time, min and pressure, bar 
A) Main effects plot (data means) for means of Reb A concentration
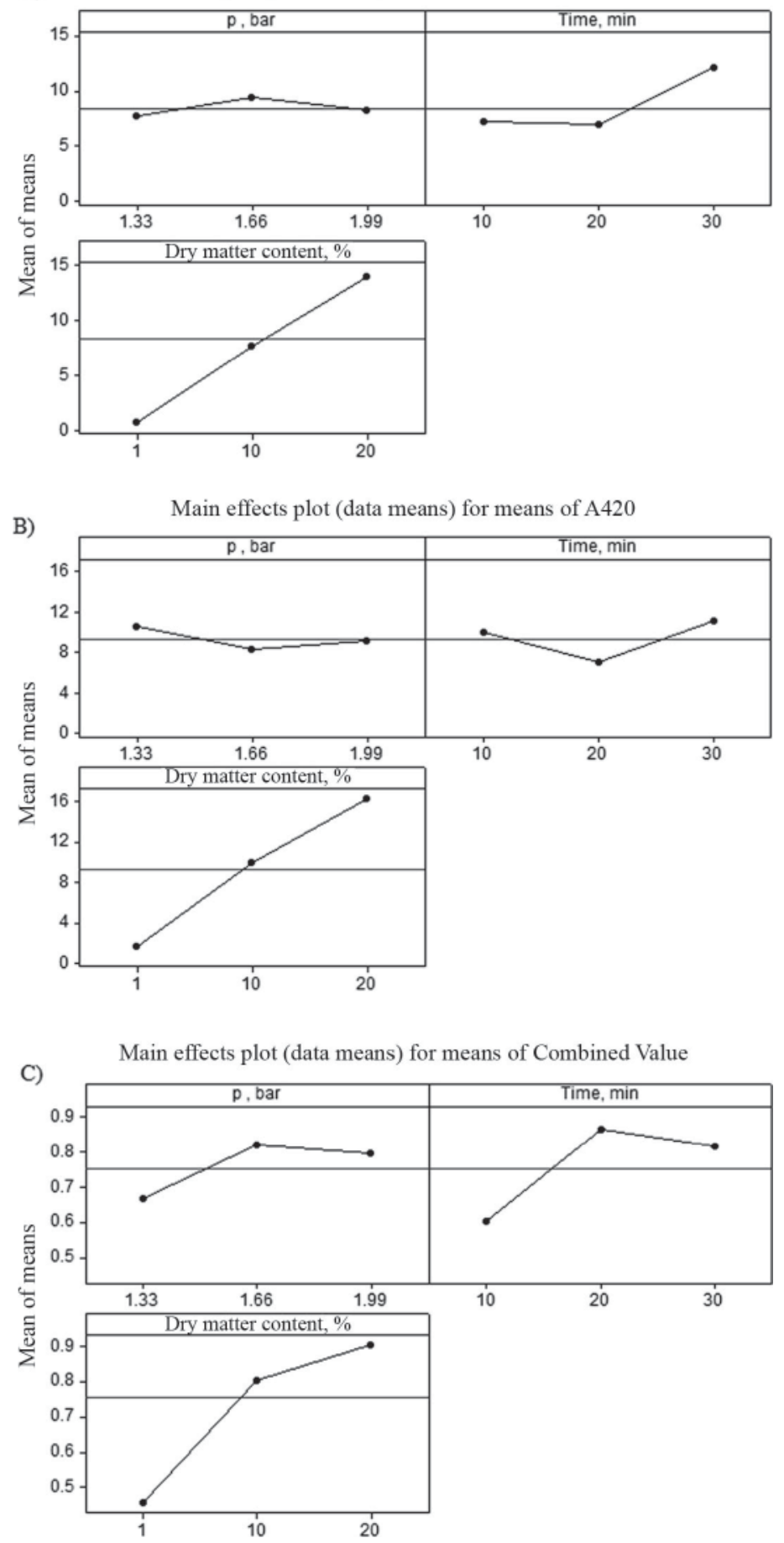

Fig. 4. Effects of factors on A) achieved Reb A concentration, B) observed colouring contaminants, C) combined value 


\subsection{First attempts to prepare a sweetener with high stevioside content}

Purified steviosides are commercially available, but many of them are manufactured synthetically. It is hard to compete with synthetic steviosides, however, a simple and efficient extraction technique may produce a competitive bio-sweetener.

Therefore, and to verify the previous optimization parameters, the optimal parameter setup (i.e. 2 bars of pressure, 20 min reaction time, and $20 \%$ dry leaves to water ratio) was applied to $200 \mathrm{~g}$ of dried stevia leaves, which absorbed almost the total amount of the water applied as solvent. With the help of a 21 wine press, $650 \mathrm{ml}$ of dark brown primer juice was recovered with an excellent content of steviol glycoside: $38.66 \mathrm{~g} \mathrm{l}^{-1}$ of stevioside and $10.66 \mathrm{~g}$ $\mathrm{I}^{-1}$ of Reb A were present, which is equal to $25.13 \mathrm{~g}$ of stevioside and $6.93 \mathrm{~g}$ of Reb A in 650 $\mathrm{ml}$ of water. While the average concentrations of the reported stevioside and Reb A in Table 1 were 70.18 and $26.6 \mathrm{mg} \mathrm{g}^{-1}$ plant, respectively (i.e. $96.76 \mathrm{mg} \mathrm{g}^{-1}$ total concentration of steviol glycoside), our PHWE and wine-press techniques yielded 125 and $34.7 \mathrm{mg} \mathrm{g}^{-1}$ (i.e. $159.7 \mathrm{mg} \mathrm{g}^{-1}$ total concentration of steviol glycoside), respectively. Thus, our overall steviol glycoside content is higher than literature data listed in Table 1.

Finally, $300 \mathrm{ml}$ of primer juice was spray dried, and $16.27 \mathrm{~g}$ of a brownish-green and slightly hygroscopic powder was obtained, which had an overall steviol glycoside content of 54\% (42\% stevioside and 11.6\% Reb A).

The UV-Vis spectra of the primer juice and the powder product resulted from spray drying were compared, and it was found that 3 peaks (at 486, 524, and $557 \mathrm{~nm}$ ) had been eliminated from the initial 8 peaks (at $303 \mathrm{~nm}, 398 \mathrm{~nm}, 429 \mathrm{~nm}, 464 \mathrm{~nm}, 486 \mathrm{~nm}, 524 \mathrm{~nm}$, $557 \mathrm{~nm}$, and $670 \mathrm{~nm}$ ) (Fig. 5). This is equal to a $17 \%$ removal of the contaminants according to the areas of the peaks.

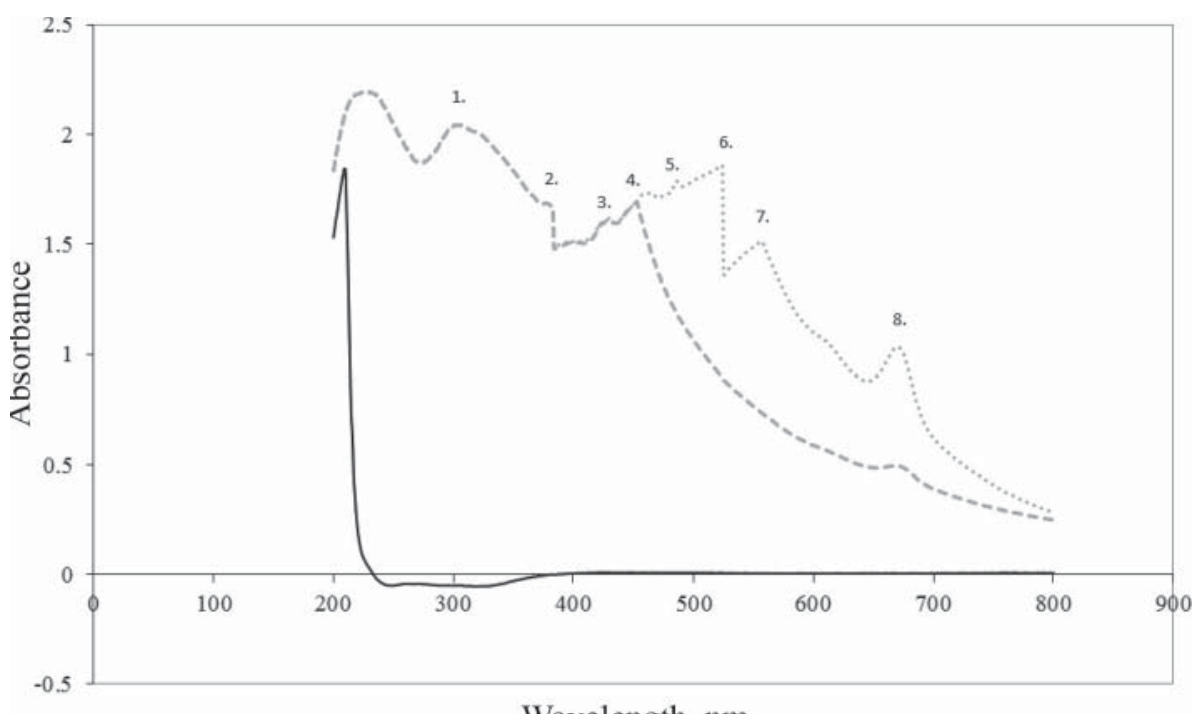

Wavelength, nm

Fig. 5. UV-Vis spectra of the primer juice (dotted line) and spray-dried primer juice (dashed line) in comparison to Reb A (solid line)

(1., 2. etc: peak maxima) 
While the single spray drying removed some components from the extracts, the obtained powder contains several other compounds beside Reb A on the basis of the spectrums. Since apart from Reb A and steviosides several other sweet components can be present in stevia extracts, we did not want to remove any additional peaks, especially, since spray drying provided a stable and sweet product formula.

\section{Conclusions}

By modelling existing industrial processes, a sweetener containing more than $50 \%$ of steviol glycosides of a stable powder formulation was successfully manufactured using three simple techniques (PHWE, wine pressing, and spray drying). It contains as few coloured compounds as possible, and the yield with respect to the dried Stevia rebaudiana Bertoni leaves is comparable to or even higher than reported values. Such results provide a strong basis to continue our research in this way, namely with the aim of creating a processing technique for stevia plants cultivated and harvested in Hungary.

While this study only focused on primer juice, further extraction cycles of the residue of the plant, by applying the presented method that involves PHWE and wine pressing, could increase the yield of steviol glycoside recovered, because our preliminary results showed that the secondary juice is similar in composition to the primer juice, therefore, our research is going to be extended in that direction as well.

The authors would like to express their gratitude to Stevia Product Europe Ltd. (Hungary) for providing the raw material furthermore to Béla Janzsó for his services during spray drying and to Agro- and Food Biotechnological Researching and Developing Ltd. (MÉL Biotech K+F Kft.) for giving financial support and supplying a small-scale grape press.

\section{References}

Chhaya, K., Sharma, C., Mondal, S., Majumdar, G.C. \& De, S. (2012): Clarification of stevia extract by ultrafiltration: Selection criteria of the membrane and effects of operating conditions. Food Bioprod. Process., 90, 525-532.

Erkucuk, A., Akgun, I.H. \& Yesil-Celiktas, O. (2009): Supercritical $\mathrm{CO}_{2}$ extraction of glycosides from Stevia rebaudiana leaves: Identification and optimization. J. Supercrit. Fluid., 51, 29-35.

Henderson, J.W. \& Berry, J. (2009): Isocratic stevia sweetener analysis using selective ZORBAX columns. Application note - Agilent. Available at: https://www.agilent.com/cs/library/applications/5990-3933EN.pdf (Last accessed: 07.01.2017)

JAITAK, V., BANDNA, B.S. \& KAUL, V.K. (2009): An efficient microwave-assisted extraction process of stevioside and rebaudioside-A from Stevia rebaudiana (Bertoni). Phytochem. Analysis, 20, 240-245.

KeARney, J. (2010): Food consumption trends and drivers. Philos. T. R. Soc. B., 365, 2793-2807.

Kolb, N., Herrera, J.L., Ferreyra, D.J. \& Uliana, R.F. (2001): Analysis of sweet diterpene glycosides from Stevia rebaudiana: Improved HPLC method. J. Agr. Food Chem., 49, 4538-4541.

Kumari, N., Rana, R.C., Sharma, Y.P. \& Kumar, S. (2017): Extraction, purification and analysis of sweet compounds in Stevia rebaudiana Bertoni using chromatographic techniques. Indian J. Pharm. Sci., 79, 617-624.

Kutowy, O., Zhang, Q. S. \& Kumar, A. (1999): Extraction of sweet compounds from Stevia rebaudiana Bertoni, US Patent No. 5972120

Lê, K.-A., Robin, F. \& Roger, O. (2016): Sugar replacers: from technological challenges to consequences on health. Curr. Opin. Clin. Nutr., 19(4), 310-315. 
Lemus-Mondaca, R., Vega-Galvez, A., Zura-Bravo, L. \& Ah-Hen, K. (2012): Stevia rebaudiana Bertoni, source of a high-potency natural sweetener: A comprehensive review on the biochemical, nutritional and functional aspects. Food Chem., 132, 1121-1132.

LIU, J., LI, J.-W. \& TANG, J. (2010): Ultrasonically assisted extraction of total carbohydrates from Stevia rebaudiana Bertoni and identification of extracts. Food Bioprod. Process., 88, 215-221.

Makapugay, H.C., NANAYAKKaRA, N.P.D. \& Kinghorn, A.D. (1984): Improved high-performance liquid chromatographic separation of the Stevia rebaudiana sweet diterpene glycosides using linear gradient elution. J. Chromatogr. A, 283, 390-395.

Markosyan, A. (2012): Food ingredients from Stevia rebaudiana: US 20120329884 A1, Google Patents.

Mathur, S., Bulchandani, N., Parihar, S. \& Shekhawat, G.S. (2017): Critical review on steviol glycosides: Pharmacological, toxicological and therapeutic aspects of high potency zero caloric sweetener. Int. J. Pharmacol., 13, 916-928.

Plaza, M. \& Turner, C. (2015): Pressurized hot water extraction of bioactives. TrAC-Trend. Anal. Chem., 71, 3954

Pól, J., Varaďová Ostrá, E., Karásek, P., Roth, M., Benešová, K., KotlaŘíková, P. \& Č́áslavský, J. (2007): Comparison of two different solvents employed for pressurised fluid extraction of stevioside from Stevia rebaudiana: Methanol versus water. Anal. Bioanal. Chem., 388, 1847-1857.

Puri, M., Sharma, D., Barrow, C.J. \& Tiwary, A.K. (2012): Optimisation of novel method for the extraction of steviosides from Stevia rebaudiana leaves. Food Chem., 132, 1113-1120.

Rajab, R., Mohan, K.C., Murugan, K., Harish, M. \& Mohanan, P.V. (2009): Purification and toxicity studies of stevioside from Stevia rebaudiana Bertoni. Toxicology International, 16, 49-54.

Rao, A.B., Reddy, G.R., Ernala, P., Sridhar, S. \& Ravikumar, Y.V.L. (2012): An improvised process of isolation, purification of steviosides from Stevia rebaudiana Bertoni leaves and its biological activity. Int. J. Food Sci. Tech., 47, 2554-2560.

Serfaty, M., Ibdah, M., Fischer, R., Chaimovitsh, D., Saranga, Y. \& Dudai, N. (2013): Dynamics of yield components and stevioside production in Stevia rebaudiana grown under different planting times, plant stands and harvest regime. Ind. Crop. Prod., 50, 731-736.

Singla, R. \& JAITAK, V. (2016): Synthesis of rebaudioside A from stevioside and their interaction model with hTAS2R4 bitter taste receptor. Phytochemistry, 125, 106-111.

VAnĚK, T., Nepovim, A. \& VAličEK, P. (2001): Determination of stevioside in plant material and fruit teas. J. Food Compos. Anal., 14, 383-388.

Zhang, S.Q., Kumar, A. \& Kutowy, O. (2000): Membrane-based separation scheme for processing sweeteners from stevia leaves. Food Res. Int., 33, 617-620.

Open Acces statement. This is an open-access article distributed under the terms of the Creative Commons Attribution 4.0 International License (https://creativecommons.org/licenses/by/4.0/), which permits unrestricted use, distribution, and reproduction in any medium, provided the original author and source are credited, a link to the $\mathrm{CC}$ License is provided, and changes - if any - are indicated. (SID_1) 